\title{
A Retrospective Study on the Prevalence of HIV among Patients Attending a Tertiary Care Hospital of Northeast India
}

\author{
Naba Kumar Hazarika1, Syed Tanwir Alam², Arunjyoti Sarmah ${ }^{3}$, Arnabjyoti Bhagawati \\ ${ }^{1}$ Department of Microbiology, Gauhati Medical College \& Incharge ICTC \& SRL, GMCH, Guwahati, India \\ ${ }^{2}$ Department of Microbiology, Gauhati Medical College, Guwahati, India \\ ${ }^{3}$ Research Scientist I (Medical), Department of Microbiology, Gauhati Medical College, Guwahati, India \\ ${ }^{4}$ Technical Officer, ICTC \& SRL GMCH, Guwahati, India \\ Email: drnkhazarika@rediffmail.com, tanwir.alam@nic.in
}

Received 17 May 2016; accepted 25 June 2016; published 28 June 2016

Copyright (C) 2016 by authors and Scientific Research Publishing Inc.

This work is licensed under the Creative Commons Attribution International License (CC BY).

http://creativecommons.org/licenses/by/4.0/

(c) (i) Open Access

\begin{abstract}
Objective: The main objective of this study is to evaluate the prevalence of HIV infection among the clients attending ICTC, Gauhati Medical College \& Hospital, Guwahati, for a period of seven years, i.e., from April 2008 to March 2015. Material \& Method: A total of 40,983 clients attended ICTC, Gauhati Medical College \& Hospital from the year 2008 to 2015. Serum samples were collected after taking informed consent and pre-test counseling. In India for all ICTCs, NACO (National AIDS Control Organization), a national guidelines has been followed for HIV testing, reporting and release of results with post test counseling. Results: Of the total 40,983 clients tested for HIV infection, 1919 (4.68\%) were found to be HIV seropositive. Seropositivity was higher in male clients i.e. $1314(68.47 \%)$ than female i.e. 604 (31.47\%) followed by transgender (TG), i.e., $1(0.0005 \%)$. Heterosexual route of transmission was the major route seen in 1666 clients (86.81\%). Maximum HIV seropositivity was in the age group of $45-49$ years $(43.62 \%)$. Conclusion: HIV prevalence of $4.68 \%$ among the clients attending ICTC, Gauhati Medical College \& Hospital, Guwahati, puts the spotlight on the HIV burden in this part of the country and suggests the need for the scaling up of focused prevention efforts in high-risk groups.
\end{abstract}

\section{Keywords}

Northeast India, HIV, ICTC, Transgender 


\section{Introduction}

India registered its first case of HIV way later than in other parts of the world, but in the present scenario HIV has established itself as a major public health problem with tremendous social and economic implications. The risk behaviors and practices associated with an enhanced risk of transmission of HIV in India include Intravenous drug use, unprotected sexual inter-course, and transfusion of contaminated blood and blood products. Heterosexual route is the commonest route of transmission in India, being associated with the other assessory factors like presence of untreated ulcerative STIs, irregular use of condoms, frequency of sexual contact, and age at sexual initiation. HIV is an infection which many people have stigma, prejudices or negative attitudes about, which can ultimately result in people with HIV being insulted, gossiped about, rejected and excluded from social activities [1].

With rising global awareness and efforts for the effective treatment and prevention programmes, a new hope has dawned recently in the global AIDS epidemic. Recently, India also has launched NACP IV with its continuous commitment. There are approximately 3.4 crores people currently living with HIV and about 3 crores people have died of AIDS related causes since the beginning of the epidemic [2]-[4]. Latest worldwide survey data show a 50\% reduction in the rate of new HIV infections (HIV incidence) achieved in 25 (twenty five) low and middle income countries between 2010 and 2011. India with a burden of 2.5 million people with HIV-1 infection makes it only the third largest HIV-1 epidemic in the world after Africa and Nigeria. The target of zero new HIV infection from 2.5 million new HIV infections (i.e. the figure in 2011) is quite faraway and there is required a herculean effort to accelerate HIV prevention programmes [5]. India contributes to nearly $60 \%$ of South Asia's total HIV epidemic [6].

Researchers from NACO opined that HIV/AIDS epidemic in the north-eastern states are spread primarily by intravenous drug-users who then pass it on to their partners by means of unprotected sexual intercourse. Amongst the Northeastern states, Nagaland leads the list followed closely by Mizoram. Out of the nearly two lakhs IDUs users in India, a staggering 50,800 are from the states of Nagaland, Mizoram, Manipur and Meghalaya. It has been found that over $20 \%$ of them are HIV+ solely due to sharing of contaminated needles [7].

In 1992, Government of India expressed its commitment to combat the disease by launching the first National AIDS Control Programme (NACP-I) as a comprehensive programme for prevention and control of HIV/AIDS in India [5]. Looking to counter the immense challenge of the HIV/AIDS threat in India, NACO has a response to increase access to services and effectively communicate for behavior change. The concept of integrating the preventive and care services was indicated through the initiation of ICTCs in GMCH, Guwahati. An ICTC [8] is a place where a person is counselled and tested for HIV, of his own free will or as advised by a medical provider. The main functions of an ICTC are:

- Conducting HIV diagnostic tests.

- Providing basic information on the modes of HIV transmission, and promoting behavioural change to reduce vulnerability.

- Link people with other HIV prevention, care and treatment services.

The ICTC provides pre-test counseling and testing, apart from the post-test counseling and support services. Clients which include general population and high-risk groups excluding antenatal cases utilize the services of the centre on voluntary basis.

\section{Aims and Objectives}

This study was carried out retrospectively to estimate the prevalence of HIV infection in the clients attending ICTC at GMCH, Guwahati situated in Northeastern India.

The present study has documented the prevalence and risk factor of HIV infection among the clients attending ICTC, GMCH (including general clients, HRGs excluding antenatal women).

\section{Materials and Methods}

Ours is a retrospective study of the clients who attended ICTC, GMCH, Guwahati of Northeastern India from April 2008 to March 2015. All the clients attending the ICTC were counseled and informed consent was taken from them by ICTC counselors. The basic client data including name, age, sex, occupation, education, marital status, risk factor associated were properly documented in the lab register by ICTC counselors. All clients at 
ICTC were given unique PID number and he/she was directed for collection of samples ( 3 - $5 \mathrm{ml}$ of blood) at the primary sample collection room at ICTC. Then HIV test was done in the HIV Laboratory, as per NACO guidelines with the 3 rapid test kits provided by ASACS/NACO [9].

The protocol of the rapid tests performed as per NACO guidelines [9] was as follows: The first test kit was of highest sensitivity and the specificity increases with second and third kit. Therefore, when the test with first kit is negative, the sample is not subjected to testing by the second and third kit tests and the result is negative for that tested sample. If however, the first test is positive, and then the second and third rapid kit tests were performed and if these two tests were also positive, then the final result was given as positive for that tested sample [9].

\section{Results and Observations}

In this study the prevalence of HIV was found to be $4.68 \%(1,919 / 40,983)$. Out of total 40,983 clients, 1919 (4.68\%) tested positive for HIV. Majority of seropositivity was found in male clients (68.47\%), followed by $31.47 \%$ in female clients and $0.001 \%$ in transgender (Table 1 ). By definition Transgender is a term used to describe those people who experience a mismatch between their gender identity, or gender expression, and their assigned sex. Transgender people are sometimes called transsexual if they desire medical assistance to transition from one sex to another [10]. The prevalence of seropositivity is depicted in Figure 1.

An alarmingly increasing trend of seropositivity from $3.78 \%$ in 2008 to $6.93 \%$ in 2015 was observed over the period of study (Figure 1). We have divided the clients into different age groups viz. Childhood (0 - 14 Yrs), Adolescent (15 - 24 Yrs), Adulthood (25 - 44 Yrs), Middle age (45 - 49 Yrs) and Elderly (>50 Yrs). Maximum number of clients tested seropositive in the age group of $45-49$ years (43.62\%), followed by $36.16 \%, 8.49 \%$, $7.56 \%$ and $4.12 \%$ in the age groups of 25 - 44 years, 15 - 24 years, above 50 years and $0-14$ years of age respectively. The comparative seropositivity in different age groups is depicted in Figure 2, Figure 3 and Table 2.

When the male:female ratio was analyzed in the different age groups highest male to female ratio $(4.37: 1)$ was observed in the age group of $>50$ years followed by 2.77:1 in clients of age group $45-49$ years. Almost similar ratio of male to female clients was observed in 25 - 44 years of age group. However the ratio of male to female clients in the age group of 15 - 24 years was almost same i.e. 1.06:1 (Figure 4). However, a reverse ratio of 0.68:1 is observed in the age group of $0-14$ years. Overall male to female ratio of the seropositive group over the years 2008, 2009, 2010, 2011, 2012, 2013, and 2014 was 2.56:1, 1.64:1, 2.69:1, 2:1, 1.80:1, 2.35:1 and 2.44:1 respectively (Figure 2).

Heterosexual route was the major form of transmission (86.81\%) with male to female ratio of 2.15:1 followed by the route of mother to child transmission (4.43\%), unknown reason of transmission (2.39\%). Through Homosexual route the transmission was 3.34\%. Least transmission was observed by blood and blood products i.e. $0.006 \%$. However, the transmission through the use of infected syringes/needles was found to be alarmingly high at $2.39 \%$. The mother to child transmission was observed more in females compared to males $(0.77: 1)$ (Table 3).

Table 1. Seroprevalence of HIV clients.

\begin{tabular}{|c|c|c|c|c|c|c|c|c|c|}
\hline 8 year wise & $\begin{array}{l}\text { Total no of } \\
\text { clients }\end{array}$ & $\begin{array}{l}\text { Negative } \\
\text { clients }\end{array}$ & $\begin{array}{l}\text { Positive } \\
\text { clients }\end{array}$ & Male & PC male & Female & PC female & TG & PC TG \\
\hline 2008-2009 & 6029 & 5800 & 228 & 164 & $71.9 \%$ & 64 & $28.1 \%$ & 0 & $0.0 \%$ \\
\hline 2009-2010 & 7267 & 7029 & 238 & 148 & $62.2 \%$ & 90 & $37.8 \%$ & 0 & $0.0 \%$ \\
\hline 2010-2011 & 7066 & 6811 & 255 & 186 & $72.9 \%$ & 69 & $27.1 \%$ & 0 & $0.0 \%$ \\
\hline 2011-2012 & 5682 & 5403 & 279 & 186 & $66.7 \%$ & 93 & $33.3 \%$ & 0 & $0.0 \%$ \\
\hline 2012-2013 & 5105 & 4822 & 283 & 182 & $64.3 \%$ & 101 & $35.7 \%$ & 0 & $0.0 \%$ \\
\hline 2013-2014 & 5099 & 4791 & 308 & 216 & $70.1 \%$ & 92 & $29.9 \%$ & 1 & $0.3 \%$ \\
\hline 2014-2015 & 4735 & 4407 & 328 & 232 & $70.7 \%$ & 95 & $29.0 \%$ & 0 & $0.0 \%$ \\
\hline Total & 40,983 & 39,063 & 1919 & 1314 & $68.47 \%$ & 604 & $31.47 \%$ & 1 & $0.0005 \%$ \\
\hline
\end{tabular}




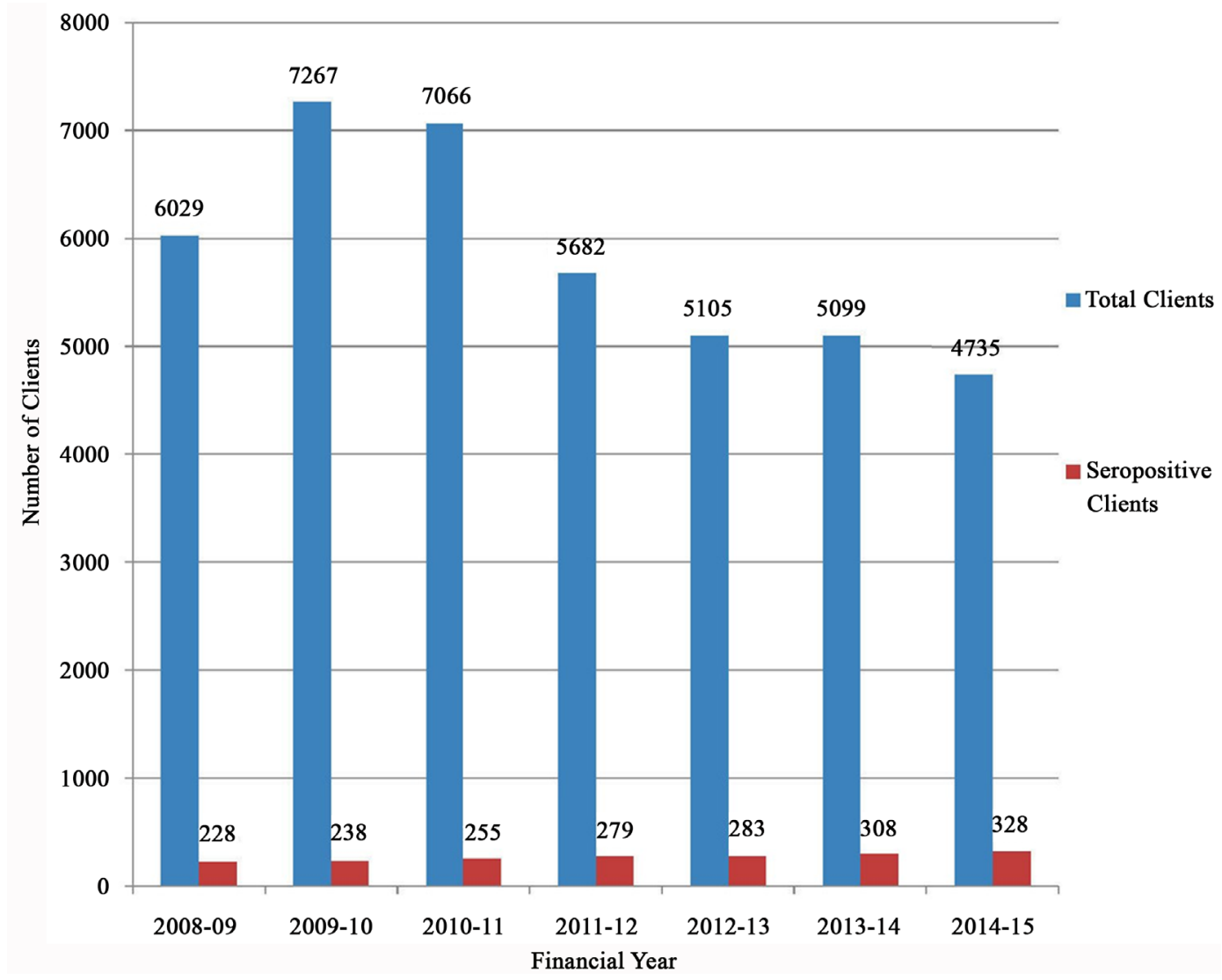

Figure 1. Seroprevalence of HIV clients.

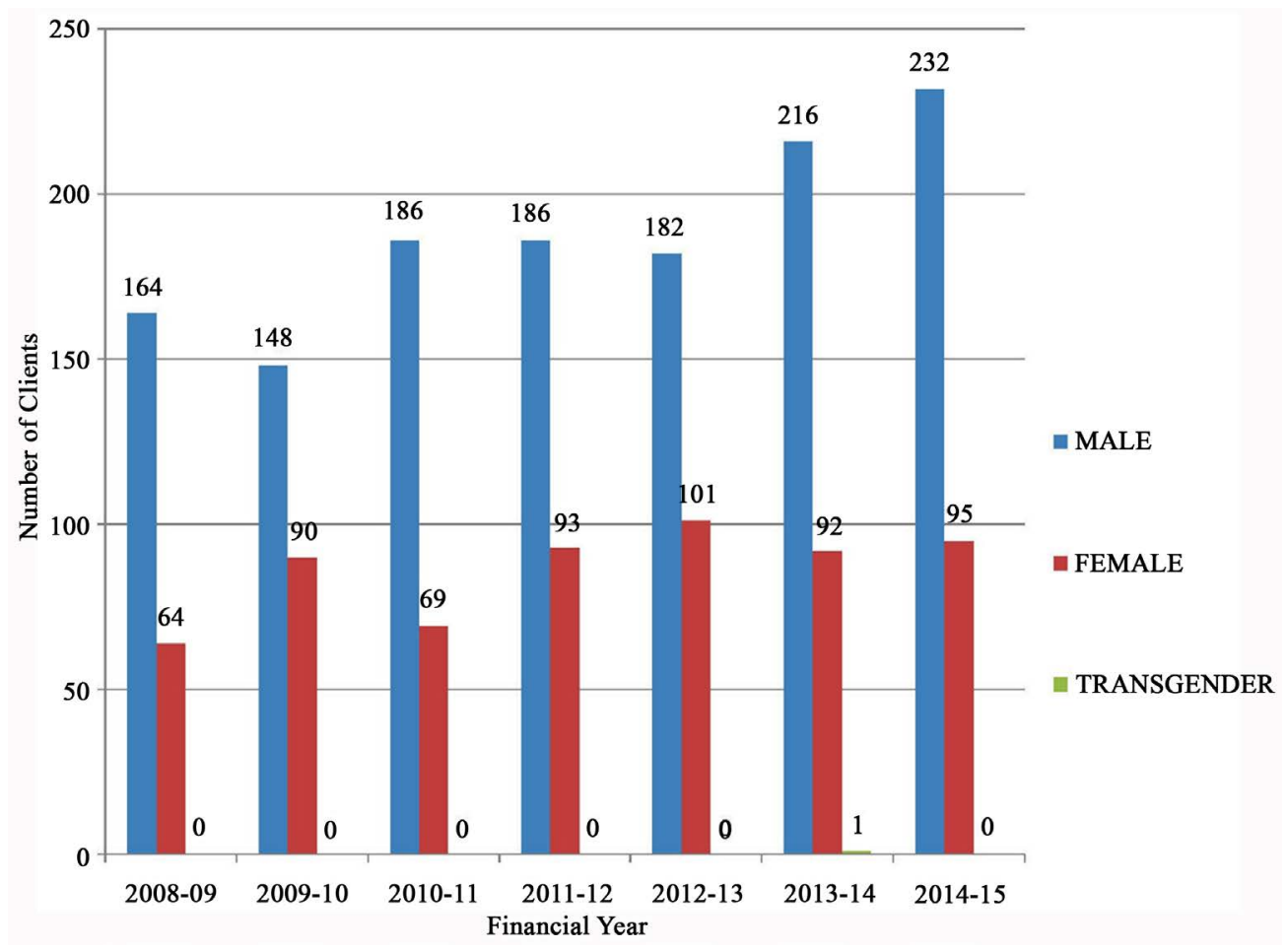

Figure 2. Sex wise distribution of seropositive clients. 

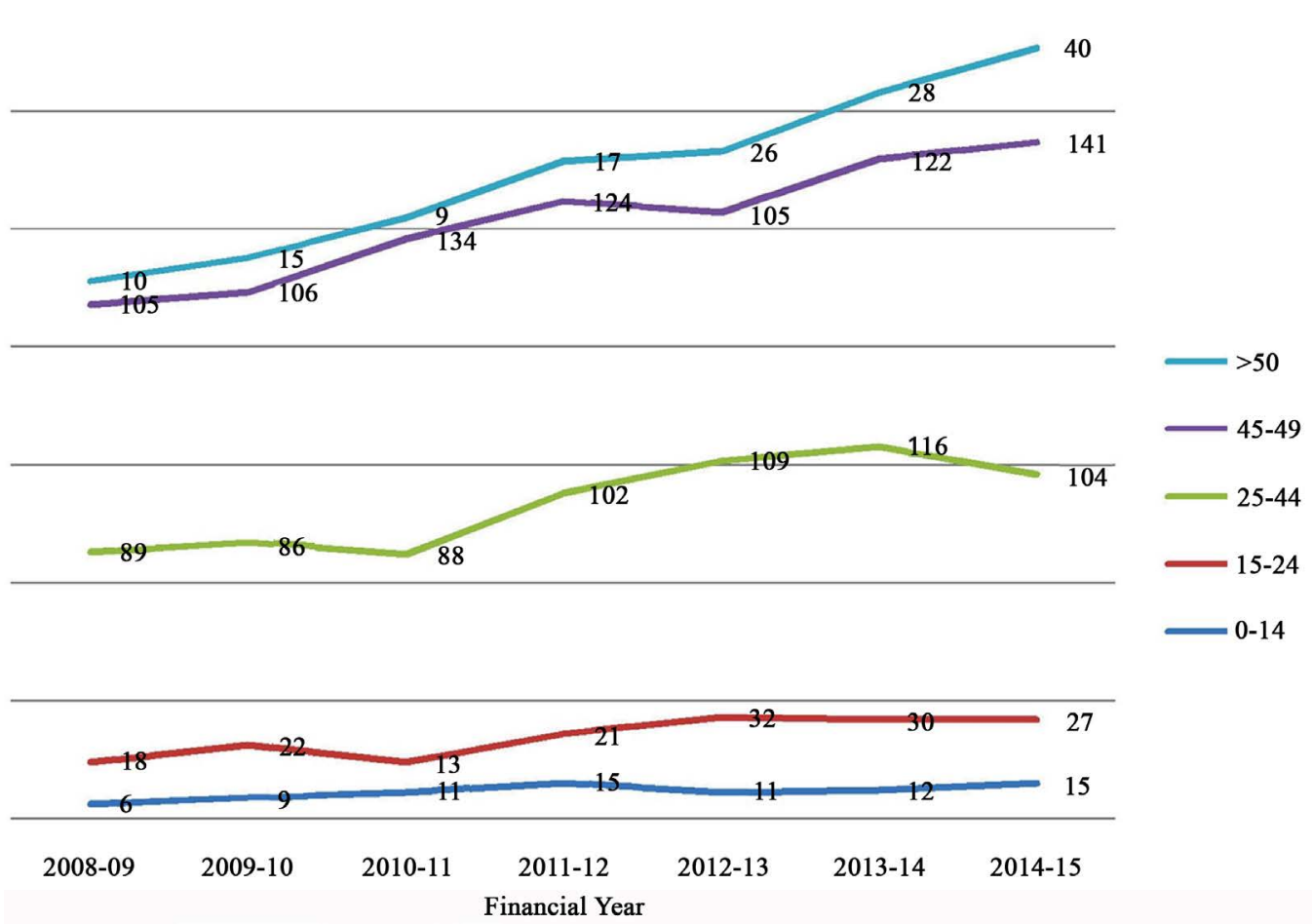

Figure 3. Age wise trend of seropositive cases over the study period.

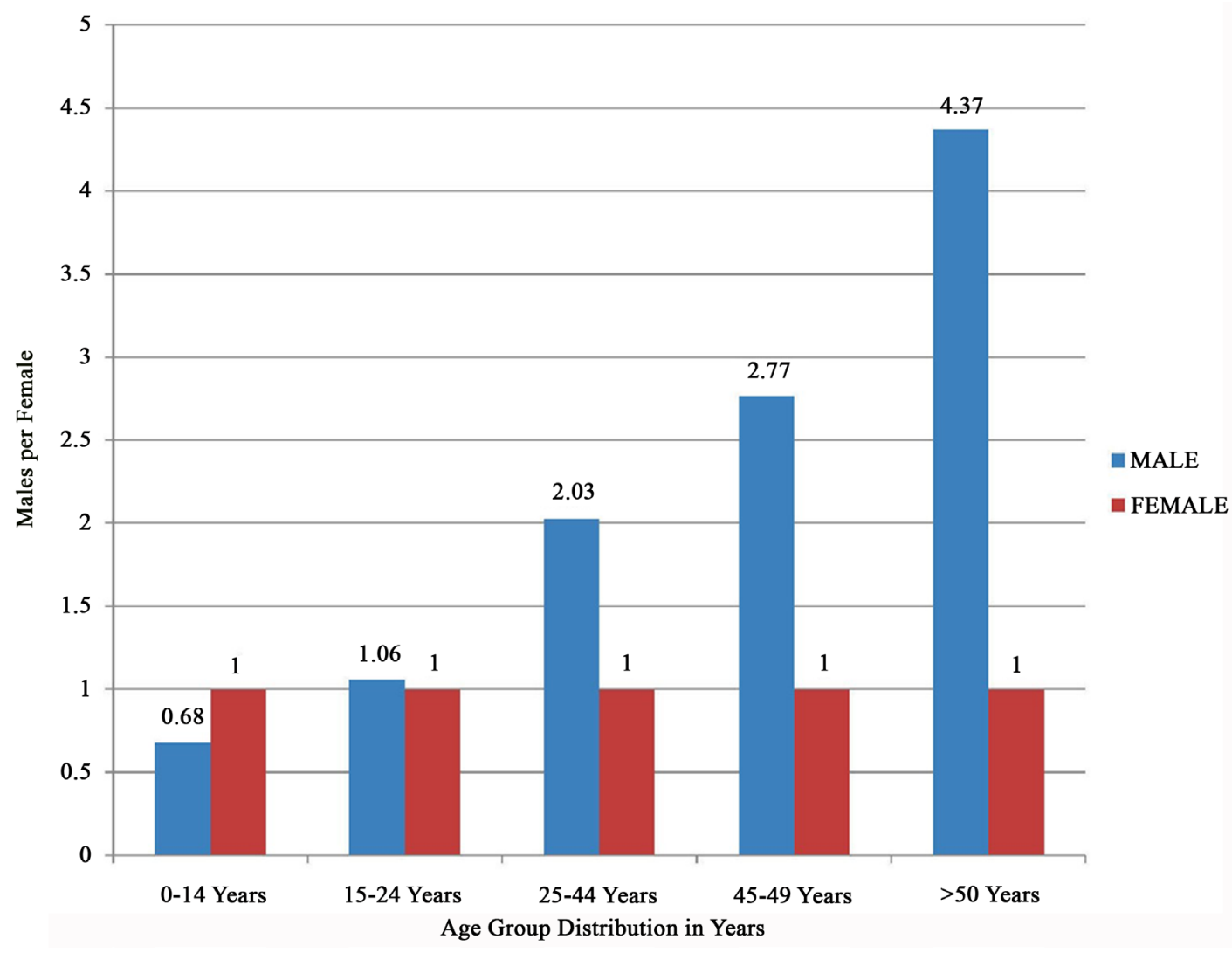

Figure 4. Ratio of male: female according to the age distribution. 
Table 2. Age \& Sex wise distribution of seropositive clients.

\begin{tabular}{|c|c|c|c|c|c|c|c|c|c|c|c|c|c|c|}
\hline \multirow{3}{*}{ Year } & \multicolumn{13}{|c|}{ Age group in yrs } & \multirow{3}{*}{$\begin{array}{l}\text { Ratio } \\
\text { M:F } \\
\text { year } \\
\text { wise }\end{array}$} \\
\hline & \multicolumn{2}{|c|}{0 - 14} & \multicolumn{2}{|c|}{$15-24$} & \multicolumn{2}{|c|}{$25-44$} & \multicolumn{2}{|c|}{$45-49$} & \multicolumn{2}{|c|}{$>50$} & \multicolumn{3}{|c|}{ TOTAL } & \\
\hline & $\mathbf{M}$ & $\mathbf{F}$ & $\mathbf{M}$ & $\mathbf{F}$ & $\mathbf{M}$ & $\mathbf{F}$ & $\mathbf{M}$ & $\mathbf{F}$ & $\mathbf{M}$ & $\mathbf{F}$ & $\mathbf{M}$ & $\mathbf{F}$ & TG & \\
\hline 2008-2009 & 2 & 4 & 13 & 5 & 58 & 31 & 84 & 21 & 7 & 3 & 164 & 64 & 0 & 2.56 \\
\hline 2009-2010 & 3 & 6 & 8 & 14 & 50 & 36 & 75 & 31 & 12 & 3 & 148 & 90 & 0 & 1.64 \\
\hline 2010-2011 & 6 & 5 & 9 & 4 & 53 & 35 & 110 & 24 & 8 & 1 & 186 & 69 & 0 & 2.70 \\
\hline 2011-2012 & 7 & 8 & 7 & 14 & 63 & 39 & 93 & 31 & 16 & 1 & 186 & 93 & 0 & 2.00 \\
\hline 2012-2013 & 3 & 8 & 11 & 21 & 77 & 32 & 73 & 32 & 18 & 8 & 182 & 101 & 0 & 1.80 \\
\hline 2013-2014 & 5 & 7 & 17 & 13 & 85 & 31 & 87 & 35 & 22 & 6 & 216 & 92 & 1 & 2.35 \\
\hline 2014-2015 & 6 & 9 & 19 & 8 & 79 & 25 & 93 & 48 & 35 & 5 & 232 & 95 & 0 & 2.44 \\
\hline Total & 32 & 47 & 84 & 79 & 465 & 229 & 615 & 222 & 118 & 27 & 1314 & 604 & 1 & 2.18 \\
\hline (\%) & $40.5 \%$ & $59.5 \%$ & $51.5 \%$ & $48.5 \%$ & $67.0 \%$ & $33.0 \%$ & $73.5 \%$ & $26.5 \%$ & $81.4 \%$ & $18.6 \%$ & $68.5 \%$ & $31.5 \%$ & & \\
\hline
\end{tabular}

Table 3. Route of transmission wise distribution of sero-positive clients.

\begin{tabular}{|c|c|c|c|c|c|c|c|c|c|c|c|c|}
\hline \multirow[t]{2}{*}{ Year } & \multicolumn{2}{|c|}{ Heterosexual } & \multicolumn{2}{|c|}{ Homosexual } & \multicolumn{2}{|c|}{ Through blood } & \multicolumn{2}{|c|}{ Infected syringes/needles } & \multicolumn{2}{|c|}{ Mother to child } & \multicolumn{2}{|c|}{ Non specified } \\
\hline & $\mathbf{M}$ & $\mathbf{F}$ & $\mathbf{M}$ & $\mathbf{F}$ & $\mathbf{M}$ & $\mathbf{F}$ & $\mathbf{M}$ & $\mathbf{F}$ & $\mathbf{M}$ & $\mathbf{F}$ & $\mathbf{M}$ & $\mathbf{F}$ \\
\hline 2008-2009 & 147 & 59 & 8 & 0 & 2 & 0 & 5 & 0 & 1 & 5 & 1 & 1 \\
\hline 2009-2010 & 125 & 75 & 4 & 1 & 1 & 1 & 3 & 1 & 5 & 6 & 10 & 6 \\
\hline 2010-2011 & 157 & 61 & 12 & 0 & 2 & 1 & 2 & 0 & 6 & 5 & 7 & 2 \\
\hline 2011-2012 & 159 & 82 & 3 & 0 & 0 & 1 & 10 & 1 & 7 & 6 & 8 & 2 \\
\hline 2012-2013 & 160 & 90 & 8 & 0 & 1 & 0 & 9 & 0 & 3 & 8 & 0 & 3 \\
\hline 2013-2014 & 188 & 81 & 14 & 0 & 0 & 0 & 7 & 1 & 5 & 7 & 2 & 3 \\
\hline 2014-2015 & 202 & 80 & 14 & 0 & 0 & 3 & 7 & 0 & 10 & 11 & 0 & 1 \\
\hline Total & 1138 & 528 & 63 & 1 & 6 & 6 & 43 & 3 & 37 & 48 & 28 & 18 \\
\hline
\end{tabular}

\section{Discussion}

The study was conducted to document the prevalence and risk factors of HIV infection among a large number ( $\mathrm{N}=40983$ ) of clients attending ICTC (excluding ANC clients) in a tertiary care hospital situated in Northeast India. Present study shows seropositivity of $4.68 \%$ among clients attending this ICTC. This is very high as compared to the seroprevalence among the general population (0.34\%). Although Assam as such is not a high prevalence state and in Assam HIV prevalence in general population is 0.09\% [11], high seroprevalence in this area as seen in our study is attributable to inclusion of clients in this ICTC from High-Risk Groups (HRG) like NGO's, MSM's, and Transgender, a majority of whom are dwellers of bordering High prevalence states like Manipur and Nagaland.

Over the years there was seen a significant increase in the percentage of positive clients from 3.78\% (51/173) in the year 2008-2009 to 6.93\% (93/245) in 2014-2015. This may be attributed to either increasing global awareness about the disease; decreasing associated stigma, expanded coverage and the widespread availability of anti retroviral therapy (ART).

Another interesting observation is that barring 2008-2009, the total number of clients tested each year shows a declining trend. This is attributable to the establishment of newer ICTC centres in Assam which has led to de- 
centralization of tested clients. The actual total is increasing each year but the number being tested in ICTC, GMCH has declined since.

The significant difference in male to female positivity ratio $2.56: 1,1.64: 1,2.70: 1,2: 1,1.80: 1,2.35: 1$ and 2.44:1 in the years 2008-2009, 2009-2010, 2010-2011, 2011-2012, 2012-2013, 2013-2014 and 2014-2015 respectively shows that females are still lagging behind in availing the medical facilities as much as by males. In our study, the positivity rate was significantly low in females in comparision to males but Vyas et al. [12] in their comprehensive six years (2002-2007) ICTC based study shows that the positivity rates were infact found to be higher among females. According to Madkar et al. [13], male to female ratio in HIV seropositivity was 3.09:1.

It is observed that in the age group ranging from 15 - 49 years, the seropositivity rate is $88.27 \%$ which resonates well the study by Vyas et al. [12] where the positivity rate ranges from $85.99 \%$ to $90.55 \%$ in the age group of 15 - 49 years. In the study, it was seen that prevalence of HIV infection was highest in the sexually active age group of 25 - 49 years (79.78\%) which again is supported by Madkar et al. [13] where the prevalence of HIV infection was highest in the age group of 30 - 39 years followed by 20 - 29 years. Also as per our national figure, it is observed that about $89 \%$ of the cases occurred among sexually active persons aged 20 - 49 years [14] [15].

Unprotected heterosexual contact has come out to be the most common mode of transmission of HIV in the present study with the rate of $86.82 \%$ with the male and female ratio of 2.15:1. According to Vyas et al. [12] the most common mode of transmission is also the heterosexual route of transmission in Jaipur with a prevalence rate of upto $81.6 \%$. But according to Lal et al. [14], the same rate is $84 \%$ in India.

In this study, the perinatal transmission ranged from $0.3 \%$ in the year $2008-2009$ to $1.1 \%$ in the year 2014-2015. According to Vyas et al. [12], the same was found to be ranging from $5.6 \%$ to $12 \%$ but according to Joardar et al. [16] the rate was a little lower i.e. 2.63\%. Transmission from mother to child can occur in uterus or during breast feeding. In the present study, transmission was found to be more in female child as compared to the male child $(0.77: 1)$. This ratio is in stark contrast to the overall ratio observed in various age groups. This area needs further investigation to justify the distribution and support the findings. Many more studies are warranted for validation of this observation. Strict enforcement of prevention of mother to child transmission in industrialized countries, have substantially reduced the number of children who acquire HIV [17]. In India however the scenario is far from good. Poor access to health care system, collective ignorance of the masses, financial constraints and NACO policy till recently of excluding the antenatal mothers unless the prevalence rates exceed one percent in the area may lead to increase in pediatric HIV infections in coming years [18]. Transmission through blood, blood products as well as use of infected needle/syringes as per our observation is staggeringly high i.e 3.02\%. Transmission through blood transfusions has been nearly eliminated in developed countries by the routine mandatory screening of blood donations [17]. In developing countries, transmission through the blood transfusion is yet to be checked, especially where HIV prevalence rates among blood donors are high and where screening of blood for HIV has not become routine [17]. India still has many paid blood donors; contaminated blood and blood products account for about $2 \%$ of HIV infections [19].

In this study, only 12 clients (6 male \& 6 female) gave the history of transmission through blood or blood products over the study period. It is the information provided by clients. It could not be established with surety that transmission occurred through blood products. Similarly 46 clients (43 male \& 3 female) gave history of Intravenous Drug usage by infected needle/syringes. Injection drug use (IDU) plays a critical role in the HIV epidemic in various regions, Asia and Southern Europe being of special mention. According to studies in Southeast Asia, HIV prevalence among IDUs raced away to $40 \%$ within a period of 1 to 2 years after the first positive HIV test result. This was true for Manipur and rest of North-East India, where IV drug abuse is quite common. Effective and well documented HIV prevention strategies like outreach to IDUs, peer education programs and social network interventions which has led to reduction in HIV transmission among IDUs in developed countries are now being employed in developing countries as well [17].

According to the latest UNAIDS report, India did manage to reduce its HIV count by a whopping 57 percent while the neighbouring Bangladesh and Sri Lanka saw an increase in HIV cases by 25 percent. India is not alone though in curbing the overall spread of the disease. Globally, the number of people newly infected continues to fall: the total number of people (including both adults and children) acquiring HIV infection in 2011 (25 lakhs) is 20 percent lower than in 2001. In 2011, 17 lakh people died from AIDS related causes worldwide. This represents a 24 percent decline in AIDS-related mortality compared with 2005 when 23 lakh deaths occurred [20]. India had responded promptly to the HIV/AIDS challenge at the primary stage itself by setting up 
an HIV/AIDS task force under the Indian Council of Medical Research and a National AIDS Committee led by the Secretary, Ministry of Health and Family Welfare. In 1990, a medium term plan was launched in four states (Tamil Nadu, Maharashtra, West Bengal \& Manipur) and four metropolitan cities (Delhi, Kolkata, Chennai \& Mumbai). The plan comprises of targeted IEC campaigns, establishment of surveillance system and safe supply of blood and blood products [5]. The Nation-wide response to HIV/AIDS in India over the last decade has yielded encouraging outcomes in terms of prevention \& control of HIV. Taking into consideration the fact that HIV testing in India is a voluntary testing i.e. not mandatory for every individual in the community, it is actually quite a challenging job to estimate the actual prevalence of HIV among those not attending ICTC or any of the testing centers voluntarily. The figures obtained in various studies may thus actually reflect only the tip of the iceberg. Taking this point in consideration, the prevalence of HIV in our study (4.68\%) among the clients attending our ICTC centre was much higher in comparison to the prevalence of HIV in adult Indian population i.e. $0.34 \%(0.25 \%-0.43 \%)[13]$.

\section{Summary and Conclusion}

ICTCs have an extremely important and crucial role in the prevention, detection and care of HIV infection. The ICTC-GMCH caters to a huge population being located in the heart of Guwahati and the neighboring states of Assam as well. ICTC-GMCH gives services like pre-test counseling, testing of HIV, post-test counseling communication with ART centre for treatment of positive patients. By availing these services, the centre is bearing responsibilities in terms of testing HIV infections, helping in behavioral modifications of high-risk group people through proper pre/post test counseling as well as care and support of the people living with HIV.

This study reports for the first time the prevalence of HIV among the clients attending ICTC in Gauhati Medical College, Guwahati. In our study, prevalence of HIV infection in clients attending ICTC has been ascertained to be $4.68 \%$. There is a male preponderance over female (2.03:1) in the sexually active age group of $25-44$ years of age as is the case amongst the Intravenous drug users (14.3:1).

Hence we should focus on this age group and Intravenous drug users especially male clients for the prevalence of high rate of HIV transmission. This would help in the development of the appropriate policies and strategies to reduce the spread of HIV infection in India. All these findings suggest the need for the scaling up of focused prevention efforts among these groups. Perinatal transmission was interestingly observed to be more in the female child (0.77:1). This needs to be proven by undertaking further studies.

\section{Limitation of the Study}

All clients interviewed in pre-counseling session attended the ICTC-GMCH for HIV screening on a voluntary basis or referred basis. The interview schedule included sensitive data like the history of risk behavior and history of HIV in the family or the partner. It is possible that the data reported here could be biased due to recall error or social stigma faced by the patients in the community.

\section{Acknowledgements}

The authors would like to thank Assam State AIDS Control Society (ASACS) for their support in carrying out the study. Also we would like to acknowledge the efforts of Mr. Prankanta Adhikari and the rest of the staff of ICTC, Gauhati Medical College and Hospital, without which the realization of this study would have been next to impossible.

\section{References}

[1] Narain, J.P., Jha, A., Lal, S. and Salunke, S. (1994) Risk Factors for HIV Transmission in India. AIDS, 8, S77-S82.

[2] UNAIDS (2012) Report on the Global AIDS Epidemic.

[3] UNAIDS (2012) World AIDS Day Report: Results.

[4] UNAIDS (2011) AIDS at 30: Nations at the Crossroads.

[5] NACO Annual Report 2011-12.

[6] Moses, S., Blanchard, J.F., Kang, H., et al. (2006) AIDS in South Asia: Understanding and Responding to a Heterogeneous Epidemic. The World Bank, Washington DC, 7-19. http://dx.doi.org/10.1596/978-0-8213-6757-5 
[7] https://drugfreene.wordpress.com/hivaids-situation-in-north-east-india

[8] (2007) Operational Guidelines for Integrated Counselling and Testing Centers. NACO, MOHFW.

[9] NACO Guidelines, March 2007.

[10] Altilio, T. and Otis-Green, S. (2011). Oxford Textbook of Palliative Social Work. Oxford University Press, Oxford, 380. http://dx.doi.org/10.1093/med/9780199739110.001.0001

[11] HIV/AIDS Scenario in Northeast India. http://www.avert.org/aidsindia.htm

[12] Vyas, N., Hooja, S., Sinha, P., Mathur, A., Singhal, A. and Vyas, L. (2009) Prevalence of HIV/AIDS and Prediction of Future Trends in North-West Region of India: A Six Year ICTC Based Study. Indian Journal of Community Medicine, 34, 212-217. http://dx.doi.org/10.4103/0970-0218.55286

[13] Madkar, S.S., Nilekar, S.L. and Vankudre, A.J. (2011) Prevalence of HIV Infection among Persons Attending Integrated Counseling and Testing Centre, Ambajogai. National Journal of Community Medicine, 2, 213-215.

[14] Lal, S. (2003) Surveillance of HIV/AIDS in India (Editorial). Indian Journal of Community Medicine, 27, 3-9.

[15] Park, K. (2002) Park's Text Book of Preventive and Social Medicine. 17th Edition, M/s Banarsidas Bhanot, Jabalpur, 259-267, 314-316.

[16] Joardar, G.K., Sarkar, A., Chatterjee, C., et al. (2006) Profiles of Attendees in the Voluntary Counseling and Testing Center of North Bengal Medical College in Darjeeling District of West Bengal. Indian Journal of Community Medicine, 31, $43-46$.

[17] Gayle, H.D. and Hill, G.I. (2001) Global Impact of Human Immunodeficiency Virus and AIDS. Clinical Microbiology Reviews, 14, 327-335. http://dx.doi.org/10.1128/CMR.14.2.327-335.2001

[18] Sehgal, S., Datta, U., Arora, S., et al. (2008) Time Trends of Pediatric HIV Infection in North India. Journal of the Indian Medical Association, 106, 162-164.

[19] Steinbrook, R. (2007) HIV in India—A Complex Epidemic. The New England Journal of Medicine, 356, 1089-1093. http://dx.doi.org/10.1056/NEJMp078009

[20] India Winning Battle against HIV/AIDS, December 2012.

\section{Abbreviations}

AIDS: Acquired Immune Deficiency Syndrome

ANC: Ante-Natal Care

ART: Anti-Retro Viral Therapy

ASACS: Assam State AIDS Control Society

HRG: High-Risk Group

HIV: Human Immunodeficiency Virus

IEC: Information Education and Communication

IDUs: Intravenous Drug Users

ICTC: Integrated Counseling and Testing Centre

GMCH: Gauhati Medical College \& Hospital

MSM: Man Having Sex with Man

NACO: National AIDS Control Organization

NACP: National AIDS Control Programme

NGO: Non Government Organisation

SRL: State Reference Laboratory

TG: Transgender

UNAIDS: United Nations Programme on HIV and AIDS 


\section{Submit or recommend next manuscript to SCIRP and we will provide best service for you:}

Accepting pre-submission inquiries through Email, Facebook, Linkedin, Twitter, etc A wide selection of journals (inclusive of 9 subjects, more than 200 journals)

Providing a 24-hour high-quality service

User-friendly online submission system

Fair and swift peer-review system

Efficient typesetting and proofreading procedure

Display of the result of downloads and visits, as well as the number of cited articles

Maximum dissemination of your research work

Submit your manuscript at: http://papersubmission.scirp.org/ 